\title{
Topography and distribution of ostia venae hepatica in the retrohepatic inferior vena cava
}

\begin{abstract}
P.K. Bundi, BSc. (Anat). $4^{\text {th }}$ year Medical Student, University of Nairobi, J.A. Ogeng'o, BSc. MBChB, PhD, J. Hassanali, BDS, DDS, and P.O. Odula, BSc, MBChB, MMed, FCS, Department of Human Anatomy, University of Nairobi
\end{abstract}

Corresponding author: P.K. Bundi, Department of Human Anatomy, University of Nairobi

\begin{abstract}
BACKGROUND: Openings of hepatic veins into the retrohepatic surface of the inferior vena cava (ostia venae hepatica) play a part in controlling hepatic circulation by acting as collateral channels in obstruction. Their topography and distribution must be taken into account during catheterization and liver transplantation. This anatomy is however little known among Kenyans.
\end{abstract}

OBJECTIVES: To study the position, number and distribution of ostia venae hepatica in a selected Kenyan population

MATERIALS AND METHODS: Eighty fresh postmortem liver specimens were obtained from the Chiromo Mortuary. The hepatic IVC was isolated from the lower border of caudate lobe to the diaphragmatic opening, with the liver in position. The vein was opened posteriorly by a vertical incision along its whole length and the lateral flaps reflected laterally. The topography of the ostia was studied using the Sahni model. The number and patterns of the ostia were also studied. The patterns of openings of the left, right and middle hepatic veins were studied as well as the distances between them.

RESULTS: A total of 584 ostia were identified, an average of 7.3 per liver. The ostia were distributed on the lateral portions of the vein, with an avascular plane at the centre. Major veins terminated in the upper third of the hepatic inferior vena cava, with little extraparenchymal course. The mean distance between the right hepatic vein and middle hepatic vein was $1.7 \mathrm{~cm}$

CONCLUSION: The numerous ostia venae hepatica identified in these subjects offer collateral flow channels during hepatic venous obstruction in Budd-Chiari syndrome. The topography and patterns of distribution of the openings suggest the advantage of an avascular virtual plane, which is a safe dissecting path for hepatovascular surgeons.

\section{Introduction}

The hepatic portion of the inferior vena cava (HIVC) extends from the lower border of the caudate lobe to the diaphragmatic opening. It may pass in a groove or an incomplete or complete tunnel on the posterior aspect of the liver (1). Hepatic veins and other accessory veins terminate into its anterior wall with little or no extraparenchymal course (2). Previous studies have recorded ethnic variations in the position, number and pattern of termination of ostia venae hepatica $(1,3)$.

The above information may be important during hepatic vascular surgery including the liver hanging manoeuvre where an avascular plane between the major veins is used to mobilise and rotate the liver (4). In the relief of Budd-Chiari syndrome, there is need to know the position of 
the ostia and distances between them in order to know where to insert the balloon in balloon membranotomy (5).

In spite of this surgical relevance and variability of the HIVC, it remains understudied in black Kenyans.

\section{Materials and Methods}

Eighty liver specimens, complete with the hepatic inferior vena cava, were obtained from the Chiromo Mortuary after ethical approval. All specimens were obtained from Kenyan blacks.

A midline incision was made in the anterior abdominal wall extending up from the xiphisternum to pubic symphysis. The anterior abdominal walls were retracted as far laterally as possible. The stomach and intestines were reflected to the left and then the lesser omentum was incised to reach the porta hepatis. The diaphragm and the inferior vena cava were incised as one block.

The IVC was opened posteriorly by a vertical cut extending from its upper to the lower end and the specimen washed in tap water to remove any clots of blood. The IVC was divided into nine areas using a self improved method similar to that by Sahni et al (5). The position (Figure 1), pattern of termination and the size of the ostia venae hepatica were determined. Only ostia $>5 \mathrm{~mm}$ in diameter were studied.

\section{Results}

\section{Types and patterns of openings of large hepatic veins}

The large hepatic veins which opened into the HIVC were the right hepatic vein (RHV), middle hepatic vein (MHV) and left hepatic vein (LHV). In all the cases the three veins were found in the upper third of the HIVC (Figures 1 and 2). The RHV and LHV extended a little below the diaphragm into the liver, with variable extrahepatic course. In all the cases, the RHV was found in the right area of the upper third, or area 3 of our HIVC model.
A common ostium for the MHV and LHV was observed in 50 (62.5\%) of the cases (Figure $2 \mathrm{~b})$. In this case, there were two ostia for the major hepatic veins. There were separate ostia for the MHV and LHV in $30(37.5 \%)$ of the cases (Figure 2(c)), thus three separate ostia for large hepatic veins. This study did not identify a common ostium for all the large hepatic veins (single-type). Further, the RHV was present in all the cases.

The MHV and LHV, whether opening into single or separate ostia, were always located in the left (L) area of the upper third of our HIVC model (area 1). In 60\% of the cases, the upper margin of the LHV or the combined LHV and MHV was higher than that of the RHV by average of $3.5 \mathrm{~mm}$. In $20 \%$ of the cases, the RHV was higher than the LHV or combined LHV and MHV by $2.0 \mathrm{~mm}$. These veins were at the same level in $20 \%$ instances. The mean distance between the RHV and the MHV or the combined LHV and MHV was $1.7 \mathrm{~cm}$.

Figure 1: HIVC model. The posterior wall has been opened and flaps spread laterally, and divided into 9 areas

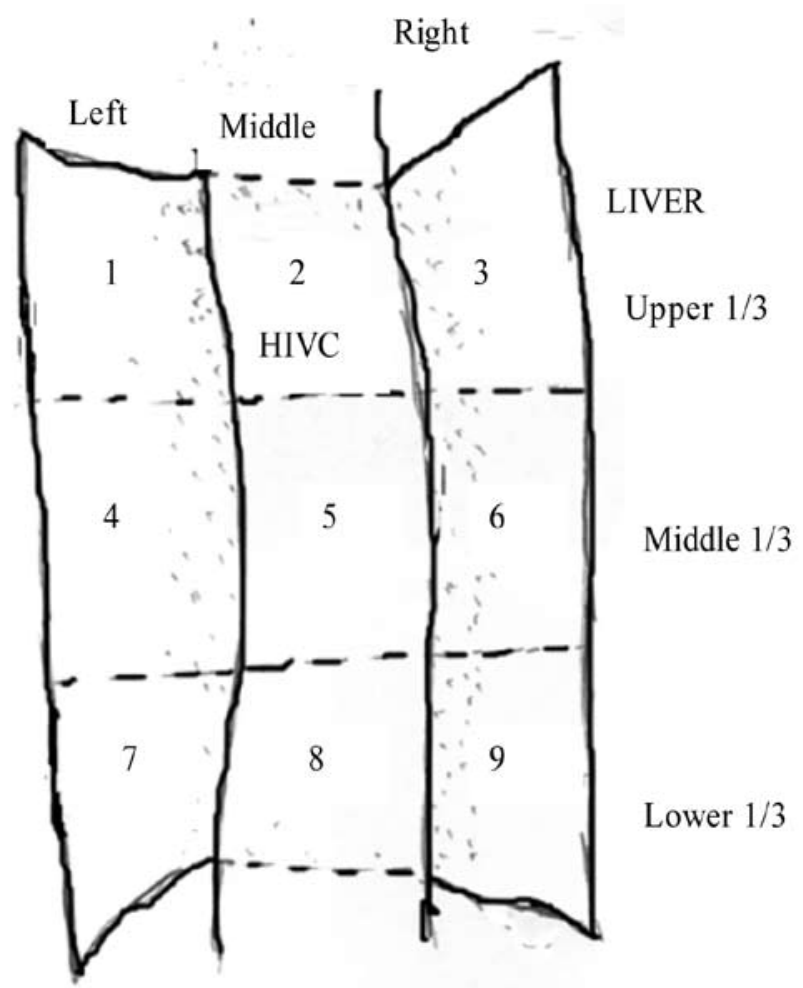


Figure 2(a): The posterior wall of HIVC has been removed showing ostia venae hepatica (arrows). The central part of the wall does not show any ostia (free zone).

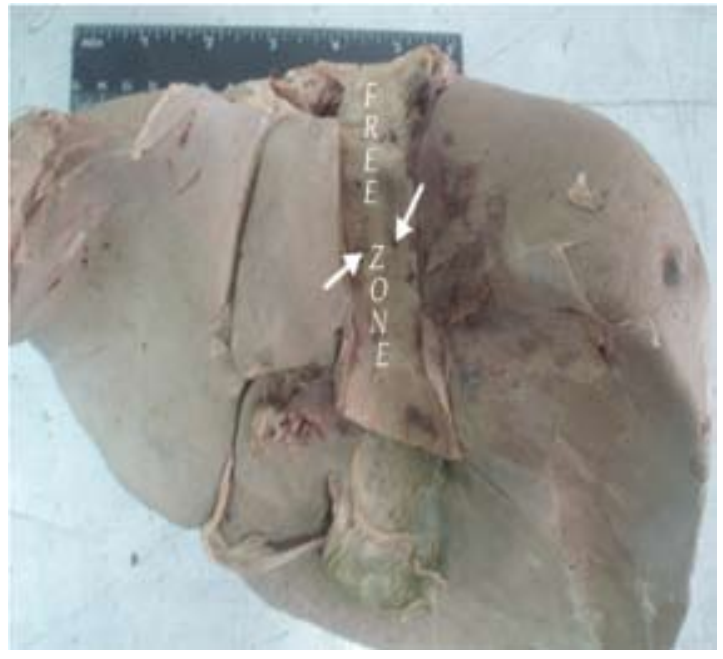

Figure 2(b): A common opening for the middle and left hepatic veins (labelled $\mathrm{C}$ ). This is a double-type opening

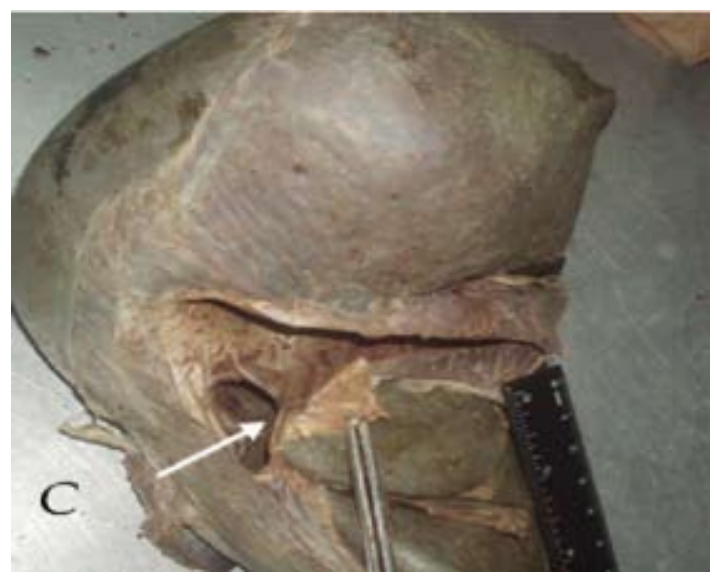

Figure 2(c): Separate ostia for middle (M), left (L) and right $(R)$ hepatic veins. This is triple-type opening. Note the distance between the MHV and RHV (d)

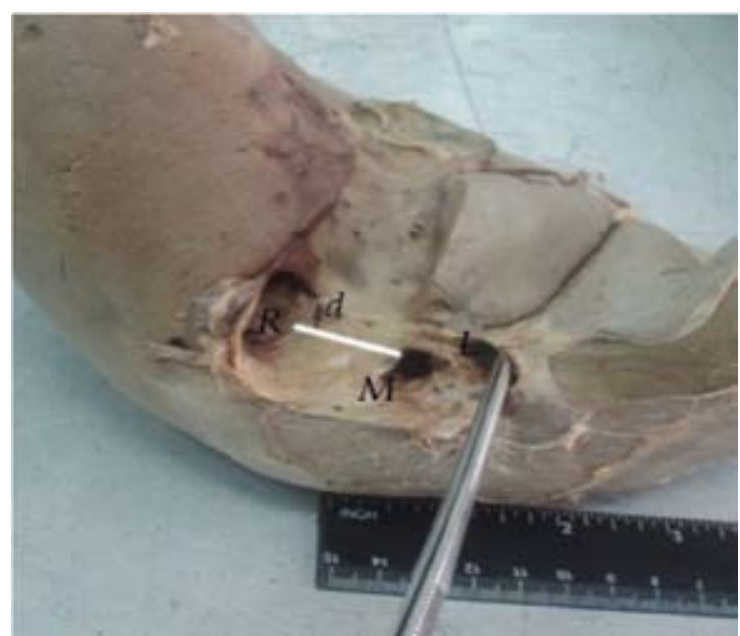

\section{Positions and number of ostia venae hepatica}

Apart from the major hepatic veins, other veins opened into the HIVC anterior wall in areas 4, 6, 7 and 9 in $90 \%$ of the cases (Figure $2 a$ ). In $10 \%$ of the cases studied, there were ostia venae hepatica in areas 5 and 8 , in addition to the other areas. No ostia were identified in area 2 . Hence, areas 2, 5 and 8 were relatively free of ostia venae hepatica. 584 hepatovenous openings were observed, bringing the average number per liver to 7.3

\section{Discussion}

The present study has demonstrated the three major hepatic veins in all hepatic segments of IVC. The RHV, MHV and LHV were all in the upper third of our HIVC model. Both the RHV and LHV had a little extraparenchymal course in all cases. The location of the major hepatic veins in the suprahepatic portion of the IVC is fairly constant, as has been reported by various workers $(1,3,5-7)$. This constant location is an advantage to the surgeon during hepatic transplantation (7). The present finding that large hepatic veins have some extraparenchymal course, is inconsistent with standard texts but agrees with the findings of Nakamura et al (3) and Chang et al (9). The presence of some extrahepatic right hepatic vein cuff is helpful during right lobe donor harvest because of ease of dissection and graft implantation on to the recipient IVC (7).

A common ostium for the MHV and LHV was found in $62.5 \%$ of the cases. This arrangement where the MHV and LHV open into a common ostium and the RHV into a separate ostium has been named the double-type opening (10). Another form of double-type opening occurs when the RHV is absent and the MHV and LHV open into separate ostia (9). This was not observed in the current study. We observed separate ostia for the three large hepatic veins, an arrangement termed the triple type opening (10), in $37.5 \%$ of the cases. A single-type opening, where the three hepatic veins open into a common ostium, has 
Table 1: comparison of the present findings on patterns of major hepatic openings and number of ostia venae hepatica

\begin{tabular}{|c|c|c|c|c|c|}
\hline \multirow[b]{2}{*}{ Author and population } & \multirow[b]{2}{*}{$\mathrm{N}$} & \multicolumn{3}{|c|}{ Patterns of openings (\%) } & \multirow{2}{*}{$\begin{array}{l}\text { Average } \\
\text { no. of ostia } \\
\text { venae } \\
\text { hepatica }\end{array}$} \\
\hline & & $\begin{array}{l}\text { LHV+MHV } \\
\text { (common) } \\
\text { Double-type }\end{array}$ & $\begin{array}{l}\mathrm{LHV}+\mathrm{MHV}+\mathrm{RHV} \\
\text { (Common) } \\
\text { Single-type }\end{array}$ & $\begin{array}{l}\text { Separate } \\
\text { LHV,MHV, RHV } \\
\text { (Triple-type) }\end{array}$ & \\
\hline Nakamura et al (1981); Japanese (3) & 83 & 84.3 & & 15.7 & \\
\hline Chang et al (1989); Chinese (9) & 60 & 88.3 & 1.7 & 10.0 & $8 . \overline{2}$ \\
\hline Camargo et al (1996); Brazilians (6) & 30 & 30.8 & 51.9 & 13.5 & 14.7 \\
\hline Hirai et al (2003); Japanese (11) & 176 & & - & - & 7.3 \\
\hline Sahni et al (2006); Indians (5) & 500 & 88.0 & - & & 8.0 \\
\hline $\begin{array}{l}\text { Bundi et al (2007); Kenyans (present } \\
\text { study) }\end{array}$ & 80 & 62.5 & - & $37 . \overline{5}$ & 7.3 \\
\hline
\end{tabular}

been described (6), but was not identified in our specimens. Table 1 summarises the patterns of openings of the hepatic veins. Knowledge of the patterns of major hepatic veins is important to the interventional hepatologist during venography and resection of the liver around the HIVC (5).

The MHV and LHV, whether combined or separate, were constantly found in area 1 of our model. We found that in $60 \%$ of the cases, the upper margin of the LHV or combined LHV/MHV was higher than that of the RHV by $3.5 \mathrm{~mm}$. In $20 \%$ of the cases, the RHV was $2.0 \mathrm{~mm}$ higher, while they were at the same level in 20\% instances. This agrees with the findings by Sahni et al (5) where the LHV or combined MHV/LHV are higher than the RHV in $54 \%$ of the cases by a range of $2-19 \mathrm{~mm}$, reverse in $28 \%$ of the cases by $2-10 \mathrm{~mm}$ and at the same level in $18 \%$ cases. We found a distance of $1.7 \mathrm{~cm}$ between the RHV and the MHV or combined LHV/MHV. This falls within the earlier reported range of $0.3-1.9 \mathrm{~cm}(5,11)$. In addition, we found no veins in the horizontal interval between the major hepatic veins. It is therefore possible to insert forceps during rotation of the liver in the hanging manoeuvre without danger of damaging any veins (11).

Apart from the large hepatic veins, other ostia venae hepatica were found to open into areas 4 , 6,7 and 9 in $90 \%$ of the cases. In only $10 \%$ of the cases were ostia venae hepatica found in areas 5 and 8 . Hence, the longitudinal plane covering areas 3, 5 and 8 was relatively free of ostia venae hepatica. This agrees with the descriptions byprevious workers. Although we used a different model, it appears that the centreline of the HIVC is relatively free of ostia venae hepatica $(9,5)$. In the present study, an average of 7.3 ostia was found per liver. This is inconsistent with the finding by Camargo et al (6) that there are 14.7 ostia per liver, but agrees with that by Hirai et al (11), who found 7.3 ostia per liver. This difference is attributable to ethnicity. Identification of a longitudinal 'avascular virtual plane' in the retrohepatic IVC is critical for guiding proper insertion of forceps during the liver hanging maneuver $(11,12)$. Diffuse distribution of short hepatic venous openings along the HIVC poses a challenge of hemorrhage during operations $(12,13)$. Our findings appear to indicate that there exists a safe dissecting path for surgeons in the centreline of the HIVC, owing to few ostia.

In conclusion, the subjects studied demonstrate numerous ostia, and an avascular plane, which offer collateral channels in case of obstruction and safe dissecting path for surgeons respectively.

\section{References}

1. Williams P.L., Banister L.H., Berry M.M., et al. Gray's Anatomy - 38th Edition. Cardiovascular system. Churchill Livingstone, 1995;London.pp. 1451-1626.

2. Chummy Sinnatamby. Last's Anatomy; regional and applied. Churchill Livingstone, tenth edition, 1999. Pg 270-271.

3. Nakamura S. and Tsuzuki T. Surgical anatomy of the hepatic veins and the inferior vena cava. Surg. Gynecol. Obstet. 1981; 152: 43-50. 
4. Kokudo N., Hiroshi I., Keiji S., et al. Ultrasonically assisted retrohepatic dissection for a liver hanging maneuver. Ann. Surg. 2005; 242: 651-654.

5. Sahni D., Jit I. and Sodhi L. Gross anatomy of the caudate lobe of the liver. J. Anat. Soc. India, 2000; 49(2): 123-126.

6. Camargo A.M.S.R., Texeira G.G. and Ortale J.R. Anatomy of the ostia venae hepaticae and the retrohepatic segment of the inferior vena cava. J. Anat. 1996; 188: 59-64.

7. Deshpande R.R., Heaton N.D. and Rela M. Surgical anatomy of segmental liver transplantation. Brit. J. Surg. 2002; 89: 1078-1088.

8. Romanes G.J. In Cunningham's Textbook of Anatomy, 12th ed., 1981.pg. 478, 958. Oxford; Oxford University Press.

9. Chang R.W.H., Shan-Quan S. and Yen W.W.C. An applied anatomical study of the ostia venae hepaticae and the retrohepatic segment of the inferior vena cava. J. Anat. 1989; 164: 41-47

10. Guo L.K. Observations of channels through the liver in Chinese. Shaanxi Med. J. 1981; 10: 6-10.

11. Hirai I., Gen M., Wataru K., et al. How should we treat short hepatic veins and paracaval branches in anterior hepatectomy using the hanging maneuver without mobilization of the liver? An anatomical and experimental study. Clin. Anat. 2003; 16: 224-232.

12. Belghiti J., Guevara O.A. and Noun R. Liver hanging manuever: A safe approach to right hepatectomy without liver mobilization. J. A. Coll. Surg. 2001; 193: 109.

13. Ettorre G.M., Vennarecci G. and Boschetto A. Feasibility of liver hanging maneuvers in orthotopic liver transplantation with inferior vena cava preservation and in liver surgery. J. Hepatobiliary Pancreat. Surg. 2004; 11: 155-158. 